А. А. Долгов ${ }^{1}$, Г. В. Золотенкова ${ }^{1,2}$, Е. Н. Титаренко ${ }^{1}$

${ }^{1}$ ГБУЗ МО «Бюро СМЭ», Москва

${ }^{2}$ Кафедра судебной медицины ФУВ ГБУЗ МО МОНИКИ им. М. Ф. Владимирского, Москва

Аннотация: В статье представлена эпидемиологическая характеристика антропологических экспертных исследований, выполненных в медико-криминалистическом отделе Государственного бюджетного учреждения здравоохранения Московской области «Бюро судебно-медицинской экспертизы» в период с 2007 по 2016 год. На основании проведенного анализа выделены проблемы, возникающие при проведении подобного рода экспертиз, предложены перспективные направления в развитии судебно-медицинской остеологии.

Ключевые слова: антропология, общегрупповые признаки личности, идентификация личности

\title{
STRUCTURED ANALYSIS OF ANTHROPOLOGICAL EXPERTISES IMPLEMENTED IN THE MEDICAL AND CRIMINALISTIC DEPARTMENT OF THE BUREAU OF FORENSIC MEDICAL EXPERTISE OF MOSCOW REGION FROM 2007 TO 2016
}

\begin{abstract}
A. A. Dolgov, G. V. Zolotenkova, E. N. Titarenko
Abstract: The article presents the epidemiological characteristics of the anthropological expert studies performed in the medical and criminalistic department of the State budgetary health care institution of the Moscow Region "Bureau of Forensic Medical Examination" in the period from 2007 to 2016. On the basis of the analysis, the problems identified in carrying out this type of examination had been highlighted, and prospective directions in the development of forensic osteology had been proposed.
\end{abstract}

Keywords: anthropology, general group characteristics of personality, identification of personality

http://dx.doi.org/10.19048/2411-8729-2018-4-1-17-21

В России ежегодно пропадают без вести десятки тысяч людей. По данным МВД России, на период январь-март 2016 года на учете ведомства находилось 20071 дело по установлению личности неопознанных трупов. За этот период только 1594 из них были прекращены в связи с установлением личности. Таким образом, по меньшей мере 18477 тел оставались неопознанными по состоянию на конец марта 2016 года [1].

В Бюро судебно-медицинской экспертизы Московской области в 2013 году поступило 687 неопознанных трупов, что составило $1,7 \%$ от общего количества поступивших трупов; в 2014 - 663 (1,5\%); в 2015 - 598 (1,3\%), в 2016 454 (0,9\%). Как абсолютные цифры, так и удельный вес неизвестных трупов остается примерно одинаковым по годам, с тенденцией к незначительному снижению [2-5]. Статистические данные неумолимо свидетельствуют о том, что более половины обнаруживаемых трупов остаются неопознанными, что приводит к нарушению прав лиц, потерявших близких, и препятствует работе правоохранительных органов. Многие из них имеют признаки насильственной смерти и следы сокрытия преступлений.

Как показывает опыт отдельных регионов (к примеру, Хабаровского края), наиболее эффективным способом решения проблемы установления личности умерших лиц является практическая организация преемственности межведомственного взаимодействия на уровне «экспертной» и «следственной» идентификации [6].

Теоретическими основами идентификации личности являются теория идентификации, разработанная в рам- ках криминалистики, и физическая (биологическая) антропология, которая в нашей стране традиционно развивается и активно используется в рамках судебной медицины [7].

Существует несколько последовательных атрибутивных уровней результата идентификационного процесса: установление биологического происхождения объектов, их тканевой, видовой, групповой и индивидуальной принадлежности. С.С. Абрамов, создавший алгоритм идентификации личности, рекомендует начинать всякое идентификационное исследование с определения общих признаков и только потом переходить к решению вопросов индивидуальной принадлежности [7]. В.Н. Звягин также подчеркивает, что обязательным этапом медико-криминалистического исследования трупа и его останков является изучение общих признаков, как представленных останков, так и объектов сравнения, с последующим сопоставлением по общим и только затем - по частным признакам $[7,8]$. Установление общих признаков позволяет сузить круг поисков, что особенно важно при планировании дальнейших высокозатратных исследований, например генетических. В условиях массовой гибели людей общие признаки служат основой для судебно-медицинской первичной сортировки идентифицируемого материала с целью уменьшения количества объектов, подлежащих сравнению посредством дополнительных методов исследования. Классический набор общих признаков (т.е. признаков, например, антропологических, закономерных для определенной группы людей) включает расовую 
принадлежность, пол, возраст, рост и серологические параметры крови $[9,10]$.

Судебно-медицинское исследование с целью отождествления личности регламентируется п. 85 «Особенности порядка производства медико-криминалистической экспертизы» ведомственного Приказа от 12 мая 2010 г. № 346н «Об утверждении Порядка организации и производства судебно-медицинских экспертиз в государственных судебно-экспертных учреждениях Российской Федерации».

В этом же пункте (85.5.1) указывается, что «при судебно-медицинском исследовании с целью отождествления личности определяют: видовую принадлежность останков, количество трупов, которым они принадлежали, их расовую, половую, возрастную принадлежность; прижизненныи рост и другие размеры тела, особенности его строения, наличие признаков имевшихся заболеваний, телесных повреждений, их характер и давность; признаки словесного портрета и другие индивидуальные особенности для установления личности по неопознанным трупам».

Таким образом, необходимость обязательного производства экспертных исследований по установлению общегрупповых признаков в рамках отождествления личности четко регламентируется действующим законодательством. Кроме того, нелишне подчеркнуть, что подобного рода исследования рекомендуется проводить именно в медико-криминалистических подразделениях. Данный вид исследований, несомненно, требует прежде всего должного уровня подготовки экспертов, соответствующего инструментария, компьютерных диагностических программ. Немаловажным фактором является и экспертный опыт выполнения антропологических исследований.

Целью настоящего исследования явилось проведение структурированного анализа антропологических экспертиз (исследований), выполненных в медико-криминалистическом отделе ГБУЗ МО «Бюро СМЭ» в период с 2007 по 2016 год.

\section{$\checkmark$ МАТЕРИАЛ И МЕТОДЫ}

Материалом исследования послужили данные ежегодных отчетов об итогах судебно-медицинской экспертной деятельности ГБУЗ МО «Бюро СМЭ» за период с 2007 по 2017 год, ежегодные отчеты медико-криминалистического отдела за период с 2007 по 2016 год, заключения и акты судебно-медицинских антропологических экспертиз (исследований) за 10 лет (671). Описательным методом на основе элементов описательной статистики проведено обобщение и структурированный анализ.

\section{$\checkmark$ РЕЗУЛЬТАТЫ ИССЛЕДОВАНИЯ}

Количество антропологических исследований за период представлено на рисунке 1. Данный график свидетельствует о достаточно стабильном уровне подобных исследований (в пределах следующих цифр: минимальное количество зарегистрировано в 2011 году - 43, максимальное в 2016 - 100) и наметившейся тенденции роста. Процентное соотношение количества выполненных экспертных исследований и экспертиз (рис. 2) отражает аналогичный тренд.

Проведенный анализ показал, что наиболее частыми местами обнаружения гнилостно измененного и скелетированного трупа, частей трупа, костных фрагментов являются лесные массивы (42\%), строительные участки (28\%), места пожарищ (18\%), заброшенные дома (9\%), водоемы (2\%). Временем года, когда регистрируется наибольшее количество обнаружения и назначения к производству, является весна - начало лета (март-июнь). Таким образом, можно говорить о «сезонном» факторе, влияющем

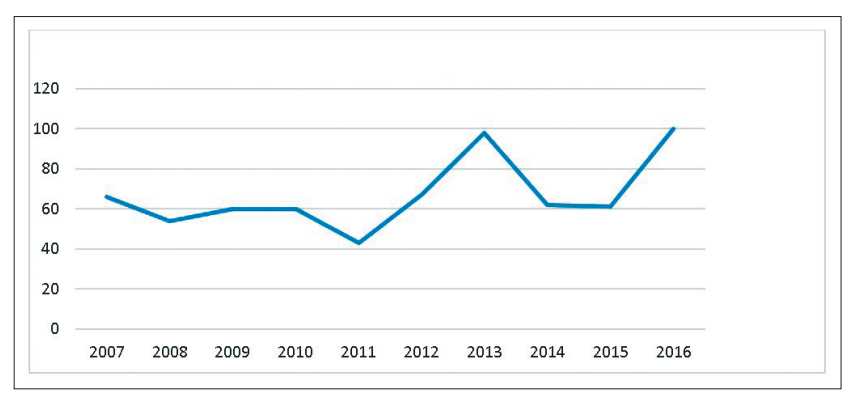

Рис. 1. Количество выполненных в медико-криминалистическом отделе исследований костных останков по данным ГБУЗ МО «Бюро СМЭ» в период 2007-2016 г2.

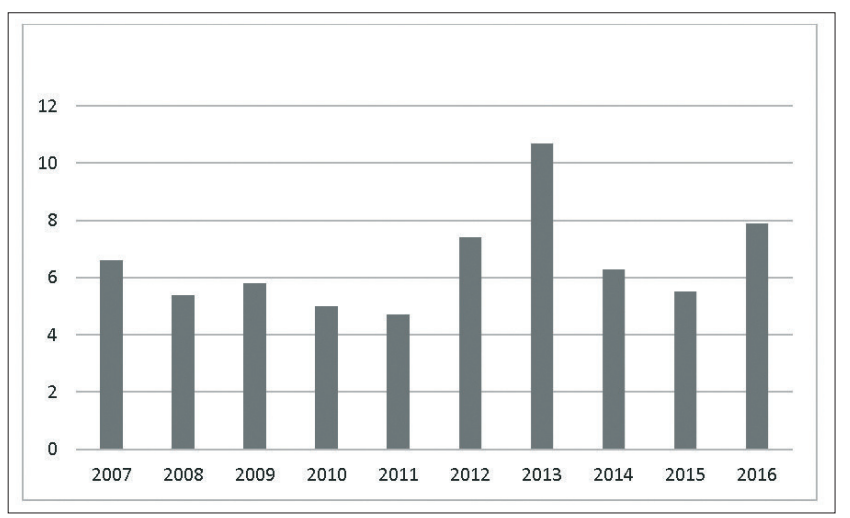

Рис. 2. Процент антропологических исследований от общего числа экспертных исследований, выполненных в медикокриминалистическом отделе, по данным ГБУЗ МО «Бюро СМЭ» в период 2007-2016 г2.

на количество антропологических исследований в тот или иной отчетный период в течение календарного года.

Количество предметов на одно антропологическое исследование за анализируемый период увеличивается и превышает почти в 1,5 раза подобный показатель других экспертиз. Среднее количество предметов в пересчете на одну экспертизу по отделу составляет 4,15. Среднее же количество поступивших на антропологическое исследование предметов составляет 7,13. О трудоемкости антропологических исследований свидетельствует превышение более чем в 1,5 раза объектов, приходящихся в среднем на одно антропологическое исследование $(14,68)$, по сравнению со средним показателем по отделу $(9,25)$. Среднее количество объект/исследований, приходящееся на одно антропологическое исследование 64,76 (минимальное 46,51, максимальное 91,61), также значительно превышает подобный показатель со средним показателем по отделу 45,51 (минимальное 38,87, максимальное 49,57). Количество же методов, применяемых в среднем на один объект как в антропологических, так и в других медико-криминалистических исследованиях и экспертизах, примерно одинаково.

Современное высокотехнологичное оснащение медико-криминалистического отдела ГБУЗ МО «Бюро СМЭ» позволяет использовать в работе новейшие приемы исследования, в том числе и компьютерные средства для выявления и регистрации общих и частных признаков объектов, а также их сравнительного анализа. Для определения пола, возраста и роста неизвестных лиц по отдельным костям применяются апробированные компьютерные программы.

Основным объектом судебно-антропологического исследования, безусловно, являются костные объекты. Главным критерием интереса исследователей к костной 
системе человека следует считать то, что костная ткань наиболее точно может соответствовать хронологической этапности физического и морфологического развития организма человека, также немаловажна высокая устойчивость данных объектов внешнему воздействию на протяжении многих лет в постмортальный период. Кроме того, методология изучения костной ткани отличается разнообразием и широким спектром методик $[6,11]$.

Диагностические исследования по установлению расовой принадлежности проводятся с использованием краниометрических и морфометрических показателей черепа, включая особенности строения зубочелюстного аппарата [6, 11].

При определении пола чаще всего используются: метрические признаки костей черепа (В.И. Пашкова, 1965), краниометрические показатели в зависимости от расы (В.Н. Звягин,1981), анатомо-морфологические признаки черепа (В.Н. Звягин, 1983), метрические признаки плечевой и бедренной костей (Й.-В.И. Найнис, 1966), костей голени (А.К. Гармус, 1974), оценка качественных признаков костей таза (А.К. Гармус), анатомо-морфологические особенности костей таза (В.И. Пашкова, В.В. Томилин, 1978), метрические признаки костей таза (В.И. Пашкова, 1978; Р. Д. Синельников, 1967) [7, 10, 11].

Установление пола по поясничным позвонкам (Д. Д. Джамолов, 1978), по лопатке (А. Л. Кошелев, 1971), по надколеннику (В.Л. Колесников, 1980), ребрам (А.И. Туровцев, 1966), ключице (3. Л. Лаптев, 1975), грудине (В.И. Добряк, 1958) носит единичный характер. Данные методики использовались менее чем в $1 \%$ от общего количества антропологических исследований, выполненных за анализируемый период.

Следует обратить внимание, что в настоящее время ощущается острая нехватка современных компьютерных апробированных методик для определения пола. Современные антропологические научные исследования и их результаты, к сожалению, не доходят до практического применения либо используются крайне редко. В некоторых случаях это имеет под собой как субъективные, так и объективные причины: это и сложность, а зачастую и невоспроизводимость существующих методик (требующих специальной подготовки и специального оборудования), и трудоемкость, сопряженная с существенными временными затратами.

Вопрос об установлении пола по фрагментам костных останков (равно как и возраста), а также предполагаемой длины тела ставился перед экспертами лишь в 10,8 \% случаев. Данное обстоятельство, возможно, связано с тем, что первоочередной задачей при исследовании представленных костных фрагментов является установление их видовой принадлежности, а также установление давности захоронения $[3,8]$. При решении данных вопросов за исследованный период в 78,6\% давность захоронения представленных костных фрагментов составляла более 25 лет. В случае определения видовой принадлежности лишь в $27 \%$ речь шла о принадлежности исследуемых костных фрагментов человеку. Здесь же следует отметить, что подобного рода экспертизы, особенно при исследовании мелких костных объектов, сопряжены с большими трудностями, обусловленными отсутствием соответствующих методик. Также отметим, что для установления видовой принадлежности представленных на экспертизу костных фрагментов в отделе успешно используется уникальный «Сравнительно-анатомический атлас установления видовой принадлежности для задач судебно-медицинской экспертизы» (В.И. Пашкова, 1967). Методики микроскопического определения видовой принадлежности, несмотря на наличие методических рекомендаций, не используются.
В первую очередь это связано с временными затратами, длительным подготовительным периодом, отсутствием программных продуктов.

Нами также проведено исследование полового состава объектов, представленных на антропологическое исследование за 5-летний период с 01.01.2012 по 31.12.2016. В полученных результатах отчетливо прослеживается тенденция преобладания костных образцов от трупов лиц мужского пола над количеством трупов женского пола. Из общего числа неизвестных костных объектов, доставленных в медико-криминалистический отдел для антропологических исследований, удельный вес последних по годам составил немногим меньше $30 \%$. Подобное распределение по половому составу характерно не только для общего массива проанализированных результатов экспертных исследований за пятилетний период, но и для каждого года в отдельности.

Определение возраста осуществляется путем краниометрии черепа и степени его инволюции (В.Н. Звягин, Ш. М. Мусаев, 1995), по швам свода черепа (Симпсон и Оливье, 1952; данные В.П. Воробьева, 1932; М. А. Гремяцкого, 1950; Г. Ф. Иванова, 1943; М. Г. Левина и Я. Я. Рогинского, 1955; В.Н. Тонкова, 1953; В. Н. Звягина, О.В. Филипчука, 1990); возрастным особенностям зубочелюстного аппарата - по степени стертости зубов (для взрослых) (М. М. Герасимов, 1955 - по зубам верхней челюсти; П.А. Максин, 1974; Н. Haishi, 1966; Takei et al., 1981; Song \& Jia, 1989); по степени стертости зубов (для взрослых) и по степени морфологических изменений твердых тканей зубов (G. Gustafson, G. Yohanson, 1950, 1971); по проксимальным отделам плечевой и бедренной костей (G. Hansen, 1953, 1954); по скелету верхней конечности (Ю.А. Неклюдов, 1992); по морфологии лонного сочленения (А.К. Гармус, 1991; J. Suchei, 1979; H. Brooks, 1990); по поясничным позвонкам (Д. Д. Джамолов, 1978); по надколеннику (В. Л. Колесников, 1980); по грудине (Э.Л. Лаптев, 1971); по локтевой и лучевой костям (Й.-В.И. Найнис и О.-В. В. Анусявичене, 1984).

Закономерно, что точность определения возраста напрямую зависит от представленных на исследование объектов, их сохранности и, что немаловажно, от выбора специалистом той или иной методики - либо их комбинации, основанной на достаточной разумности. На наш взгляд, именно способность исследователя осуществить системный подход к решению поставленных экспертных задач и должна лежать в основе принципов практической деятельности современного судебного антрополога [7, 10-17].

Следует отметить, что, помимо черепа, необходимой информативностью в контексте отображения возрастных изменений обладает лонное сочленение. В практической работе отдела при выполнении антропологических исследований с использованием костей таза, вкупе с отечественными научными разработками, нашел свое применение и метод фазной оценки морфологических признаков лобкового симфиза (система Brooks and Suchey, 1990). По данным современных зарубежных научных изданий, освещающих вопросы палеоантропологии и судебной медицины, указанная система является составной частью так называемой процедуры «двух шагов» (TSP) при определении возраста по костным останкам [18].

Наибольшее количество костных останков, представленных для антропологического исследования, принадлежало трупам неизвестных лиц, которые находились в наиболее зрелом трудоспособном возрасте в диапазоне от 30 до 55 лет, удельный вес которых приблизился к $75 \%$, без достоверных различий по годам $(\mathrm{p}>0,1)$. Удельный вес относительно молодых людей в возрасте 
16-25 лет составил не более 6,0\%, а в возрасте 26-35 лет был примерно каждый шестой из обследованных, без достоверных различий по годам ( $\mathrm{p}>0,1)$. Представители старшего возрастного контингента (от 55 лет и выше) по годам несколько превысили $10 \%$ и также не имели достоверного различия по годам $(\mathrm{p}>0,1)$.

Для определения роста по целым костям (длинные трубчатые кости: плечевая, локтевая, лучевая, бедренная, большеберцовая и малоберцовая кости) в работе отдела применяются методики с использованием данных Лорке, Мюнцнера, Вальтера, 1953; Мануврие, 1892; Пирсона, 1899; Ролле, 1888; Тельккя, 1950; Найниса, 1966; Дюпертюи и Хэддена, 1951; Троттер и Глезер, 1952.

\section{$\diamond$ выводы}

Проведенное исследование позволило нам прийти к нижеследующим выводам.

Определение общих признаков личности погибших (возраст, пол, раса, рост) является обязательным этапом при проведении судебно-медицинских экспертиз по установлению личности неизвестного трупа. В условиях массовой гибели людей определение общих признаков является основой судебно-медицинской сортировки идентифицируемого материала с целью уменьшения количества объектов, подлежащих сравнению посредством дополнительных методов исследования. Вопросы, разрешаемые судебно-медицинским экспертом при подобного рода экспертизах, требуют знания значительного числа методов диагностики и умения их практического применения.

Одной из тенденций развития судебно-медицинской науки является дополнение существующего перечня общегрупповых признаков новыми и разработка новых высокотехнологичных методик их установления. Однако, к сожалению, в настоящее время существует значительный разрыв между высоким уровнем научных разработок и реальными возможностями их практического использования в судебно-медицинских экспертных учреждениях. В связи с этим следует обратить внимание на нехватку современных рутинных методов, экспресс-методов диагностики общегрупповых признаков «у стола». Исходя из изложенного представляется актуальным вопрос о введении в практику подготовки судебно-медицинских экспертов курса по судебной антропологии.

Поиски новых, болеепростых, доступных и объективных методов исследования имеют как научный, так и значительный практический интерес. Социальная значимость подобного рода научных исследований подтверждается тем фактом, что, согласно полученным результатам антропологических исследований, выполненных за 5-летий период, наибольшее количество костных останков принадлежало трупам неизвестных лиц мужского пола, которые находились в наиболее зрелом трудоспособном возрасте (30-55 лет).

\section{$\checkmark$ ЛИТЕРАТУРА}

1. https://мвд.pф/opendata/7727739372-MVDGIAC311 Информация о розыске лиц, скрывшихся от дознания, суда, уклоняющихся от исполнения уголовного наказания, без вести пропавших, а также об установлении личности граждан и неопознанных трупов.

2. Итоги судебно-экспертной деятельности Бюро судебно-медицинской экспертизы Московской области в 2012 году: датированный ежегодник / [Клевно В.А., Зазулин В.А., Кащанов В.У. и др.]; под ред. проф. В.А. Клевно. - М.: ГБУЗ МО «Бюро СМЭ», 2013. - 40 с., ил.
3. Итоги судебно-экспертной деятельности Бюро судебно-медицинской экспертизы Московской области в 2013 году: датированный ежегодник / [Клевно В.А., Кучук С.А., Зазулин В.А. и др.]; под ред. проф. В.А. Клевно. - М.: ГБУЗ МО «Бюро СМЭ», 2014. - 40 с., ил.

4. Итоги судебно-экспертной деятельности Бюро судебно-медицинской экспертизы Московской области в 2014 году: датированный ежегодник / [Клевно В. А., Кучук С.А., Зазулин В. А., Романько Н.А., Гайдичук В.В.]; под ред. проф. В.А. Клевно. - М.: Ассоциация СМЭ, 2015. - 40 с., ил.

5. Итоги судебно-экспертной деятельности Бюро судебно-медицинской экспертизы Московской области в 2015 году: датированный ежегодник / [Клевно В. А., Кучук С.А., Зазулин В. А. и др.]; под ред. проф. В. А. Клевно. - М.: Ассоциация СМЭ, 2016. - 66 с., ил.

6. Чернышов К.А., Титаренко Е.Н., Шпанер М. А. Анализ работы отделения идентификации, исследования неопознанных трупов ГУЗ «Бюро судебно-медицинской экспертизы» министерства здравоохранения Хабаровского края за 1998-2002 гг. // Избранные вопросы судебно-медицинской экспертизы. - 2003; 6. С. $28-31$.

7. Медико-криминалистическая идентификация: Настольная книга судебно-медицинского эксперта. // Абрамов С.С., Гедыгушев И.А., Звягин В.Н. и соавт. М.: Норма-Инфра М, 2000. - 465 с.

8. Звягин В.Н. Текущие проблемы медико-криминалистической идентификации личности//Проблемы экспертизы в медицине. 2012;12:3-4: С. 39-43.

9. Алпатов И. М., Звягин В.Н., Золотенкова Г. В. Возможности оперативного проведения идентификации останков человека при сильном разрушении под воздействием физических факторов // Судебномедицинская экспертиза. 2002;4: С. 35-39.

10. Звягин В.Н., Галицкая О. И., Негашева М.А. Биометрическая сортировка трупов, разрушенных в очаге катастрофы, по признакам пола, продольным, обхватным размерам и степени подкожных жироотложений // Судебно-медицинская экспертиза. 2012;3: С. 4-11.

11. Пашкова В.И., Резников Б. Д. Судебно-медицинское отождествление личности по костным останкам. Саратов: Изд-во Сарат. ун-та, 1978. - 320 с.

12. Звягин B.Н., Анушкина Е. С. Установление видовой принадлежности костных останков // Полицейская и следственная деятельность. 2014;1: С. 178-193.

13. Гльбочко П. В., Пиголкин Ю. И., Николенко В. Н. и др. Судебно-медицинская диагностика возраста // М.: Издательство ПМГМУ им. И. М. Сеченова, 2016.

14. Найнис Й.-В.Й. Определение возраста в судебноостеологической экспертизе // Современные проблемы судебной медицины. - М.: Медицина, 1969.

15. Неклюдов Ю. А. Диагностические критерии групповых признаков индивида на скелете верхней конечности и некоторые общие вопросы судебно-медицинской остеологической экспертизы. Автореф. дисс. докт. мед. наук. - Саратов, 1985. - 35 с.

16. Пиголкин Ю.И., Федулова М.В., Золотенкова Г.В. Определение возраста человека по костной ткани. //Судебно-медицинская экспертиза. 2012;55:(1): C. $49-51$.

17. Титаренко Е.Н., Власюк И. В. Возраст человека как идентификационный признак. Методы его диагностики по данным литературы // Медицинская экспертиза и право. 2014; 3: С. 4-8.

18. Suchey-Brooks System Method for Age Determination. Proc. Am. Acad. Forensic Sci. 1997, 3:150 


\section{$\checkmark$ REFERENCES}

1. https://mvd.rf/opendata/7727739372-MVDGIAC311 Informatsiya o rozyske lits, skryvshikhsya ot doznaniya, suda uklonyayushchikhsya ot ispolneniya ugolovnogo nakazaniya, bez vesti propavshikh, a takzhe ob ustanovlenii lichnosti grazhdan i neopoznannykh trupov. (In Russian)

2. Itogi sudebno-ekspertnoi deyatel'nosti Byuro sudebno-meditsinskoi ekspertizy Moskovskoi oblasti v 2012 godu: datirovannyi ezhegodnik / [Klevno V.A., Zazulin V.A., Kashchanov V.U. i dr.]; pod red. prof. V. A. Klevno - M.: GBUZ MO «Byuro SME», 2013. - 40 s.: il. (In Russian)

3. Itogi sudebno-ekspertnoi deyatel'nosti Byuro sudebno-meditsinskoi ekspertizy Moskovskoi oblasti v 2013 godu: datirovannyi ezhegodnik / [Klevno V.A., Kuchuk S.A., Zazulin V.A. i dr.]; pod red. prof. V. A. Klevno M.: GBUZ MO «Byuro SME», 2014. 40 s.: il. (In Russian)

4. Itogi sudebno-ekspertnoi deyatel'nosti Byuro sudebno-meditsinskoi ekspertizy Moskovskoi oblasti v 2014 godu: datirovannyi ezhegodnik / [Klevno V. A., Kuchuk S.A., Zazulin V. A., Roman'ko N.A., Gaidichuk V.V.]; pod red. prof. V. A. Klevno M.: Assotsiatsiya SME, 2015.- 40 s.: il. (In Russian)

5. Itogi sudebno-ekspertnoi deyatel'nosti Byuro sudebno-meditsinskoi ekspertizy Moskovskoi oblasti v 2015 godu: datirovannyi ezhegodnik / [Klevno V. A., Kuchuk S.A., Zazulin V. A. i dr.]; pod red. prof. V. A. Klevno M.: Assotsiatsiya SME, 2016.- 66 s.: il. (In Russian)

6. Chernyshov K.A., Titarenko E.N., Shpaner M.A. Analiz raboty otdeleniya identifikatsii, issledovaniya neopoznannykh trupov GUZ «Byuro sudebno-meditsinskoi ekspertizy» ministerstva zdravookhraneniya Khabarovskogo kraya za 1998-2002 gg. // Izbrannye voprosy sudebno-meditsinskoi ekspertizy. 2003;6: S. 2831. (In Russian)

7. Mediko-kriminalisticheskaya identifikatsiya: Nastol'naya kniga sudebno-meditsinskogo eksperta. // Abramov S.S., Gedygushev I.A., Zvyagin V.N. i soavt., M., Norma-Infra M. - 2000. - 465 s. (In Russian)
8. Zvyagin V.N. Tekushchie problemy mediko-kriminalisticheskoi identifikatsii lichnosti //Problemy ekspertizy v meditsine. 2012;12:(3-4: S.39-43. (In Russian)

9. Alpatov I.M., Zvyagin V.N., Zolotenkova G. V. Vozmozhnosti operativnogo provedeniya identifikatsii ostankov cheloveka pri sil'nom razrushenii pod vozdeistviem fizicheskikh faktorov // Sudebno-meditsinskaya ekspertiza. 2002;4: S.35-39. (In Russian)

10. Zvyagin V.N., Galitskaya O.I., Negasheva M.A. Biometricheskaya sortirovka trupov, razrushennykh v ochage katastrofy, po priznakam pola, prodol'nym, obkhvatnym razmeram i stepeni podkozhnykh zhirootlozhenii // Sudebno-meditsinskaya ekspertiza. 2012;3: S. 4-11. (In Russian)

11. Pashkova V.I., Reznikov B. D. Sudebno-meditsinskoe otozhdestvlenie lichnosti po kostnym ostankam. - Saratov: Izd-vo Sarat. un-ta, 1978. - 320 s. (In Russian)

12. Zvyagin V.N., Anushkina E.S. Ustanovlenie vidovoi prinadlezhnosti kostnykh ostankov // Politseiskaya i sledstvennaya deyatel'nost'. 2014;1: S.178-193. (In Russian)

13. Glybochko P.V., Pigolkin Yu.I., Nikolenko V.N. i dr. Sudebno-meditsinskaya diagnostika vozrasta // M. M.: Izdatel'stvo PMGMU im. I.M. Sechenova, 2016 (In Russian)

14. Nainis I.-V.I. Opredelenie vozrasta v sudebno-osteologicheskoi ekspertize // Sovremennye problemy sudebnoi meditsiny. - M.: Meditsina, 1969. (In Russian)

15. Neklyudov Yu.A. Diagnosticheskie kriterii gruppovykh priznakov individa na skelete verkhnei konechnosti i nekotorye obshchie voprosy sudebno-meditsinskoi osteologicheskoi ekspertizy. Avtoref. dis. dokt. med. nauk. Saratov, 1985. - 35 s. (In Russian)

16. Pigolkin Yu.I., Fedulova M. V., Zolotenkova G. V. Opredelenie vozrasta cheloveka po kostnoi tkani. // Sudebno-meditsinskaya ekspertiza. 2012;55:(1): S.4951). (In Russian)

17. Titarenko E.N., Vlasyuk I. V. Vozrast cheloveka kak identifikatsionnyi priznak. Metody ego diagnostiki po dannym literatury // Meditsinskaya ekspertiza i pravo. 2014; 3: S. 4-8. (In Russian)

18. Suchey-Brooks System Method for Age Determination. Proc. Am. Acad. Forensic Sci. 1997, 3:150.

Для корреспонденции

ДолГОВ Алексей Александрович - заведующий медико-криминалистическим отделом, врач - судебно-медицинский эксперт ГБУЗ МО «Бюро СМЭ» •111401, г. Москва, ул. 1-я Владимирская, д. 33, корп. 1 • dolgov@sudmedmo.ru • \{SPIN-код: 8643-9826, AuthorID: 894413\}

ЗОЛОТЕНКОВА Галина Вячеславовна - к.м.н., доцент, врач - судебно-медицинский эксперт медико-криминалистического отдела ГБУЗ МО «Бюро СМЭ», доцент кафедры судебной медицины ФУВ ГБУЗ МО МОНИКИ им. М. Ф. Владимирского • 111401, г. Москва, ул. 1-я Владимирская, д. 33, корп. 1 • zolotenkova@sudmedmo.ru • \{SPINкод: 1685-1802, AuthorID: 327795$\}$

ТИТАРЕНКО Евгений Николаевич - врач - судебно-медицинский эксперт медико-криминалистического отдела ГБУЗ МО «Бюро СМЭ» • 111401, г. Москва, ул. 1-я Владимирская, д. 33, корп. 1 • 10.72@mail.ru 